\title{
SURVEY ON THE PERCEPTION OF HeALTH PROFESSIONALS ON THE USE OF INTRADIALYTIC ORAL NUTRITION IN PATIENTS UNDER HEMODIALYSIS
}

\author{
Samuel Ramos-Acevedo ${ }^{1 \S}$, Ailema J. González-Ortiz ${ }^{1 \S}$, Ricardo Correa-Rotter ${ }^{1}$, \\ Aurora E. Serralde-Zuñiga ${ }^{2}$, Paola Miranda-Alatriste ${ }^{1}$, Ximena Atilano-Carsi ${ }^{1}$, \\ EtNa Dominguez-Zambrano ${ }^{1}$ and ÁNgeles EspinOSA-CUeVAS ${ }^{1 *}$ \\ ${ }^{1}$ Department of Nephrology and Mineral Metabolism; ${ }^{2}$ Clinical Nutrition Service, Instituto Nacional de Ciencias \\ Médicas y Nutrición Salvador Zubirán, Mexico City, Mexico.
}

$\S$ These authors contributed equally to this work.

\begin{abstract}
Background: Intradialytic oral nutrition (ION) has been shown to improve many clinical outcomes, including lowering mortality, in hemodialysis (HD) patients. Despite the benefits, ION is underused in many countries. Objective: The objective of our study was to determine the perception of health-care professionals (HCP) in our environment of the use of ION in patients undergoing HD. Methods: Survey applied to HCP in Mexico who worked or had worked in an HD unit in their locality. Results: From 272 HCP who answered the survey, $74.3 \%$ believed that the use of ION has at least one beneficial effect; of these, the most frequently mentioned were an improvement in quality of life (QoL) (54.7\%) followed by an improvement in serum albumin (37.9\%) and muscle anabolism (31.6\%). However, $49 \%$ consider that its use involves some risks. Of the respondents, $22 \%$ reported that their HD units allowed patients to consume food or supplements during HD sessions; the main reason given to forbid the introduction of food or supplements was the clinic's policy (41\%). Conclusions: The personnel surveyed heterogeneous opinions regarding ION, but most believe that it may improve the QoL or the nutritional status of the patients. Nevertheless, the use of ION is uncommon in our country as it is against the internal regulations of most HD units. (REV INVEST CLIN. 2019;71:255-64)
\end{abstract}

Key words: Intradialytic oral nutrition. Dietary supplement. Health-care professionals. Hemodialysis. Nutrition therapy.

Corresponding author:

*Ángeles Espinosa-Cuevas

Department of Nephrology and Mineral Metabolism

Instituto Nacional de Ciencias Médicas

y Nutrición Salvador Zubirán

Av. Vasco de Quiroga, 15

Col. Belisario Domínguez Sección XVI, Del. Tlalpan

C.P. 14080, Mexico City, Mexico

E-mail: angeles.espinosac@incmnsz.mx

Received for publication: 19-12-2018

Approved for publication: 28-02-2019

DOI: $10.24875 / R I C .19002947$ 


\section{INTRODUCTION}

Protein-energy wasting (PEW) has been identified as a common problem in patients with chronic kidney disease (CKD), with a current prevalence of 25-70\% ${ }^{1}$. The diagnosis of PEW has been strongly associated with an increased risk of morbidity and mortality in patients on hemodialysis (HD) treatment ${ }^{2,3}$. It is well known that PEW starts from early stages of CKD and one of its main components is a low energy and protein intake of patients ${ }^{4,5}$. The components of PEW have a direct effect on caloric and protein intake. The average intake of calories in days of $\mathrm{HD}$ sessions is $22 \mathrm{Kcal} / \mathrm{Kg} \mathrm{BW}$ and, for protein, $<0.90 \mathrm{~g} / \mathrm{Kg} \mathrm{BW}^{6,7}$. The ideal values should be $30-35 \mathrm{Kcal} / \mathrm{Kg}$ and $1.1-1.2 \mathrm{~g}$ of protein $/ \mathrm{kg}$, respectively ${ }^{8,9}$. The reduced caloric and protein intake during HD is explained in part by the anorectic processes that result from the systemic inflammation present in these patients. It has been shown that between $35 \%$ and $50 \%$ of patients in HD have some degree of anorexia, which reduces their daily energy and protein intake and affects their quality of life $(\mathrm{QoL})^{10}$. Other possible causes are the diet restrictions that are often suggested by the health-care professionals (HCP) that are in contact with patients in HD, as well as the presence of gastrointestinal symptoms, the most common of these being indigestion, constipation, diarrhea, abdominal pain, reflux, and disability to eat ${ }^{11,12}$.

Intradialytic oral nutrition (ION) is a clinical nutrition strategy in which the patient is given oral supplements during HD sessions to help them meet their energy and protein needs. The use of ION has shown to increase serum albumin, improve nitrogen balance (from anabolic states), and increase patient survival ${ }^{13-15}$. Recently, a consensus for promoting this practice has been published ${ }^{16}$. Despite the good results, ION is an uncommon practice due to many theoretical and physiological aspects. Kalantar-Zadeh et al. have exposed some reasons why ION is not a common practice, such as hypotension related to mesenteric blood flow sequestration, risk of bronchial aspiration, nausea, vomiting or diarrhea, lack of glycemic control, work overload (mainly for nurses), development of harmful fauna in the HD unit (insects, rodents, etc.), infections, hygiene, and the costs that such practice represents ${ }^{17}$.
Few studies have evaluated the use of ION and have occasionally reported adverse events (such as gastrointestinal symptoms or hypotension) ${ }^{18-21}$. Strong et al. conducted a cross-sectional study to assess the frequency of intradialytic adverse events related to the ingestion of beverages and food during HD sessions; hypotension occurred in only $19 \%$ of the sessions recorded ${ }^{18}$. Despite the evidence of the benefits provided by ION and the scarce information available regarding its efficiency and safety, HCP remains reluctant to implement this nutritional therapy. The objective of our study was to determine the perception of HCP in our environment of the use of ION in patients undergoing treatment with $\mathrm{HD}$.

\section{METHODS}

\section{Study Population}

A cross-sectional study was conducted with a convenience sampling involving the application of individual surveys (previously validated by experts) on the perception and use of ION in the medical, nursing, and nutrition personnel that worked or have worked with patients on HD. The survey was conducted during two of the most important nephrology meetings in Mexico, held during the second semester of 2016. Sample calculations for physicians and dietitians were made by finite populations considering practicing nephrologists certified by the National Council of Nephrology and by the National College of Renal Dietitians in Mexico, resulting in 249 physicians and 60 dietitians. For nurses, there was no registration of practicing personnel, so the sample was calculated by infinite populations, resulting in 96 nurses.

The survey included the following aspects:

1. Demographics: profession of the subject surveyed (physician, nurse, or dietitian); their patients' age group (adult, pediatric, or both); whether they were unit chiefs or part of the general staff; city in which they worked; and type of institution in which they worked (private, public, or both).

2. Common practices in the HD unit: this section asked about the most frequent complications in the HD units (subjects were presented with a list from which they could choose more than one 
Figure 1. Flowchart of study.

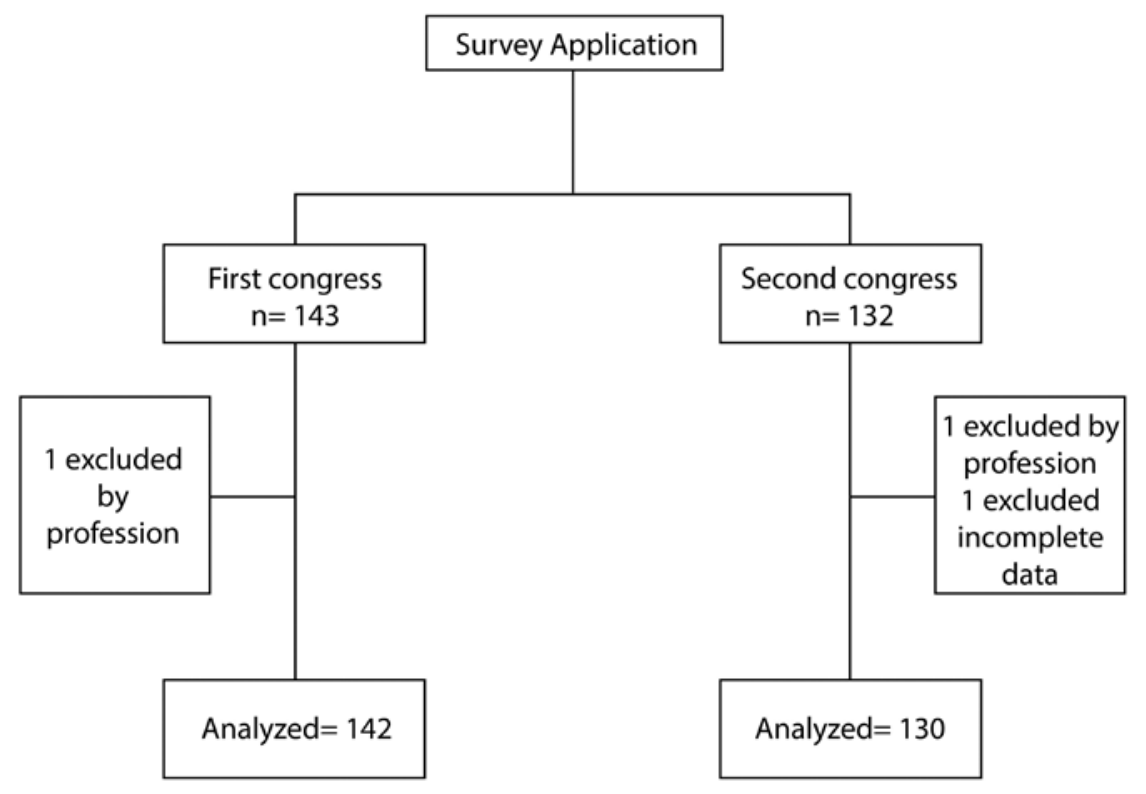

option); and whether the HD unit allowed the introduction and consumption of food during HD sessions.

3. Perception of ION: the participants were presented with five definitions of $1 \mathrm{ON}$, from which they had to choose the one they thought most convenient for their practice. The following questions aimed to know the opinion of the staff about ION, including whether they believed it had benefits or not, if it involved risks, and if so, what the risks were.

4. Reasons why they thought the practice of ION is not usual: the survey included a list of common reasons, some found in the literature and some that are usually given by other respondents of why food or supplements are not allowed during HD sessions. The participants could choose more than one option.

5. Two other questions focused on the place of academic training and the maximum level of studies.

The general characteristics of participants, such as the age group of patients with whom they work, place of the country, and type of institution where they worked, and knowledge of the concept of ION, were analyzed by grouping the participants according to their profession (physicians, dietitians, and nurses). The states in which the participants reported to have worked were grouped by regions according to the National Survey of Health and Nutrition ${ }^{22}$ : northern region; central region, capital city, and southern region. The study was conducted according to the guidelines stated in the Declaration of Helsinki.

\section{Statistical analysis}

Variables are presented as percentages or absolute or relative frequencies. The $\mathrm{Chi}$-square test or exact method of Chi-square test or Fisher's exact test was used accordingly to determine statistical differences between the groups. To evaluate the main reasons why no food or oral nutritional supplements were allowed during HD sessions, we considered only the answers of those who mentioned that their HD units did not permit it. To account for lost data, we considered relevant central tendency measurements. $p<$ 0.05 was considered statistically significant. Data were analyzed using IBM SPSS Statistics 21.0.0.

\section{RESULTS}

A total of 275 surveys were applied (Fig. 1); of these, three could not be analyzed because they had 
incomplete data or were from professionals other than physicians, nurses, or dietitians (e.g., social workers and unit managers), leaving a total of 272 surveys of HCP (137 doctors, 104 nurses, and 31 dietitians). The power sample size for physicians was 0.89 ; for nurses, it was $0.78^{23}$, and for dietitians, the sample size represented almost $50 \%$ of the renal dietitians registered in 2016 in the Mexican College of Renal Dietitians (Colegio Mexicano de Nutriólogos Renales). The majority of the participants worked with adults in the public health sector; most came from Mexico City and received their academic training in the country (Table 1).

Regarding the definition of ION, 70\% ( $n=191)$ of participants understood it as the oral administration of nutrients that patients lose during HD sessions (Table 1). Other participants considered that ION referred to parenteral supplementation or the usual diet of the renal patient. Most of the participants mentioned that they would indicate ION to patients who needed it; with less frequency, they said they would indicate it to all patients. In contrast, $26 \%$ of the participants reported that they would not indicate ION to any patient. It should be noted that dietitians did not necessarily have a clearer idea of what ION is, while physicians - although most of them did know the concept - did not apply it in their professional practice.

With respect to the routine complications that participants said to have usually observed during an HD session independently of the use of ION, the most frequently reported were intradialytic hypotension (74\%), cramps (70\%), hypertension (50.2\%), nausea or vomiting (30\%), and catheter dysfunction (26\%). Other responses were: infections (24\%), headache (22.7\%), tachycardia (12.5\%), chest pain (7\%), and somatic pain (3\%). Regarding the perception of the benefits and/or risks of ION, 74\% of the respondents perceived at least one nutritional benefit and just under half ( $49 \%$ ) believed that it also posed risks. The main perceived benefit was the improvement in QoL. It should be noted that all professionals have different perceptions of the benefits of ION, except in sleep quality, adherence to hemodialysis sessions, and electrolyte balance ( $p=$ n.s.) (Fig. 2 ). The main risk perceived by physicians and dietitians was intradialytic hypotension, and by nurses, it was bronchial aspiration (Fig. 3).
Regarding the question about whether the consumption of food was allowed during HD sessions in the centers where the participants worked, it was found that only $60(22 \%)$ of the centers allowed this practice. The participants mentioned that the main reason why they do not allow food consumption during HD session is the clinic's policy in the centers where they worked, with no statistical difference between professions $(p=0.606)$. The second main reason was the increased risk of infections (33.5\%), followed by the risk of bronchial aspiration (28.7\%); the latter was not commonly mentioned by dietitians $(p=0.001)$. Another reason mentioned was the work overload that ION can imply $(p<0.01)$. Other less frequent reasons were: lack of glycemic control (9.6\%), lack of electrolyte control ( $<5 \%$ ), lack of fluid control $(7.7 \%)$, personnel workload $(11.4 \%)$, and the increase in patient expenses (11.4\%) (Fig. 4).

\section{DISCUSSION}

ION is an anabolic strategy to improve PEW in patients with kidney disease and has shown important benefits such as decreasing catabolism, and therefore, improving patient's nutritional status, and survival rates ${ }^{13-16}$. These effects are explained by adding an average of $10 \mathrm{kcals} / \mathrm{kg}$ and $0.3-0.4 \mathrm{~g} / \mathrm{kg}$ of protein to the patient's diet ${ }^{4,24}$. However, despite this evidence and that ION is a common practice in European and Eastern Asian countries, it is not frequently used in North America ${ }^{25}$, including Mexico due to some disadvantages perceived by HCP such as changes in blood pressure during the digestion process, the risk of bronchial aspiration or infections, and the work overload of the responsible personnel ${ }^{17}$.

The present study reflects the perception of health personnel regarding the use of ION in our country. This is the second published study describing the experience in the use of ION; the first was carried out by Kistler et al. ${ }^{25}$ For our research, it was important to determine if the HCP knew the term ION. Interestingly, the majority (70\%) understood it correctly, regardless of the academic training ( $p=0.143)$, and $75 \%$ of all participants said that they would indicate it in some way. We found differences between the answers of specific HCP groups. Given the above and the fact that different studies have shown that patients in HD do not meet their energy and protein 
Table 1. General characteristics of surveyed health-care professionals

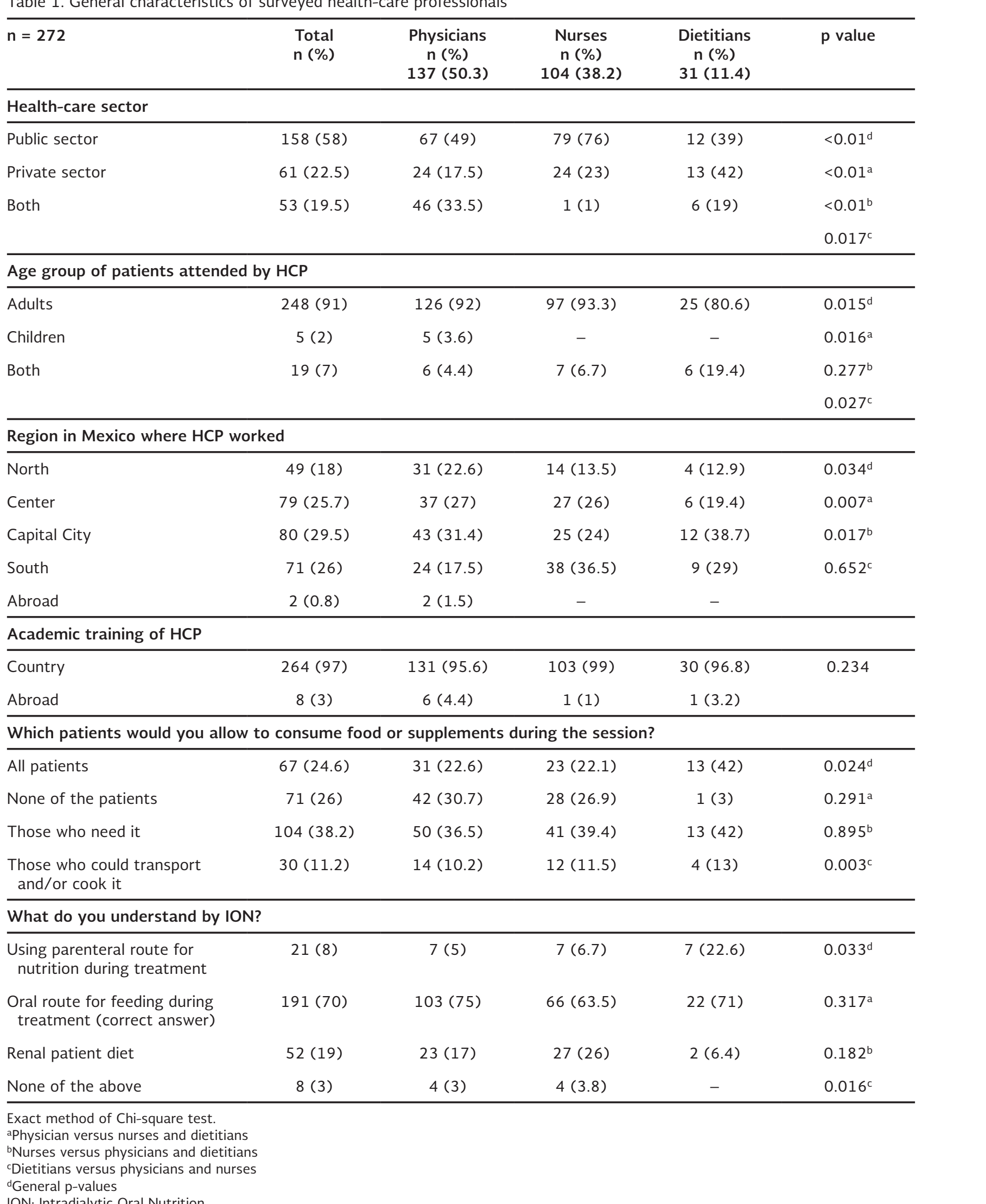

ION: Intradialytic Oral Nutrition 
Figure 2. Perception about the possible benefits for the patient with the use of intradialytic oral nutrition. (a) Physicians versus all ( $p<0.05)$, (b) nurses versus all $(p<0.05)$, dietitians versus all $(p<0.05)$, (d) all $(p<0.05)$.

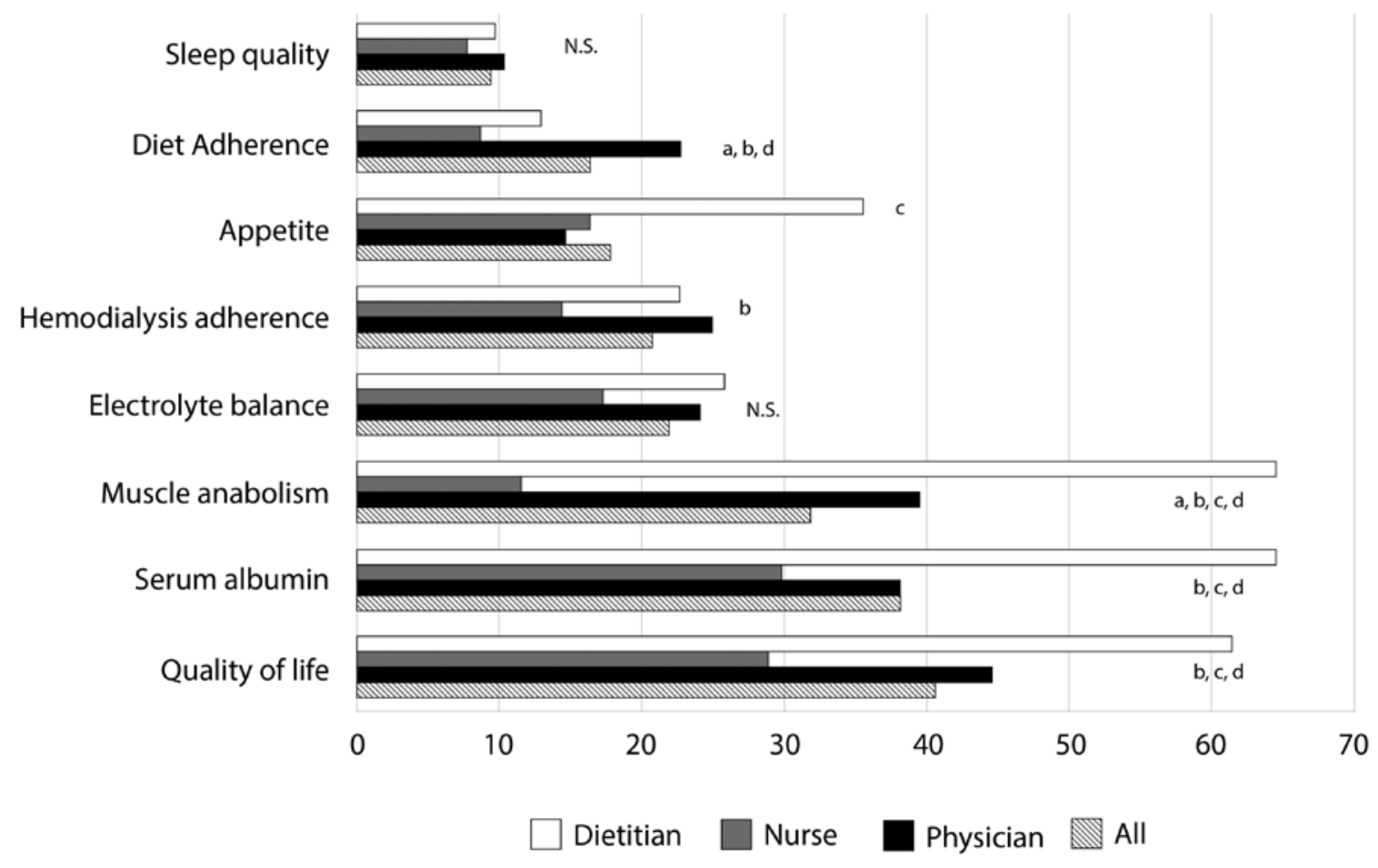

Figure 3. Main risks perceived by health-care professionals with the use of intradialytic oral nutrition.

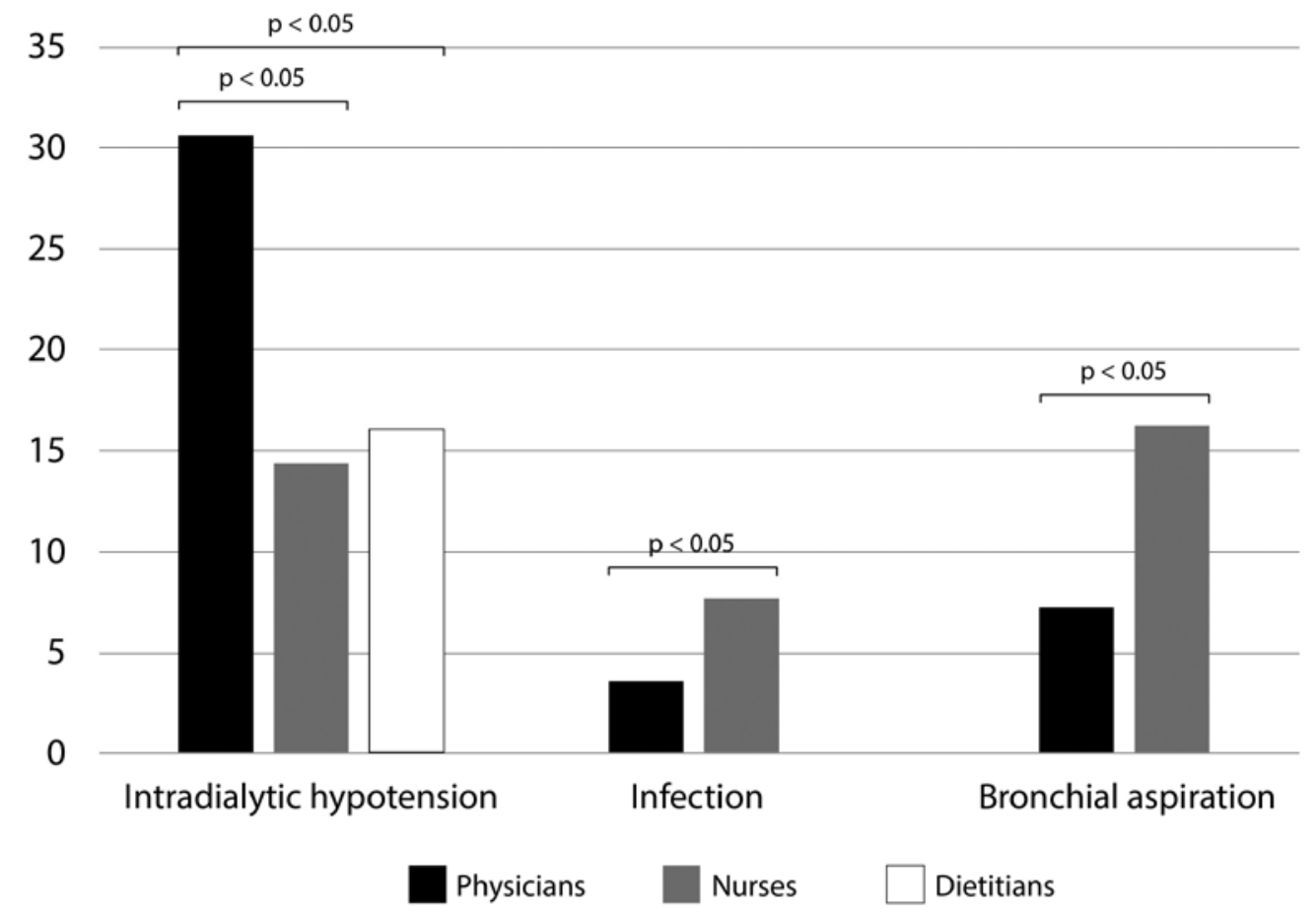


Figure 4. Main reasons why ION is not a common practice in Mexico. (a) Physicians versus all ( $p<0.05$ ), (b) nurses versus all $(p<0.05)$, (c) dietitians versus all $(p<0.05)$, (d) all $(p<0.05)$. *NOM Norma Oficial Mexicana (Official Mexican Guidelines for hemodialysis practice).

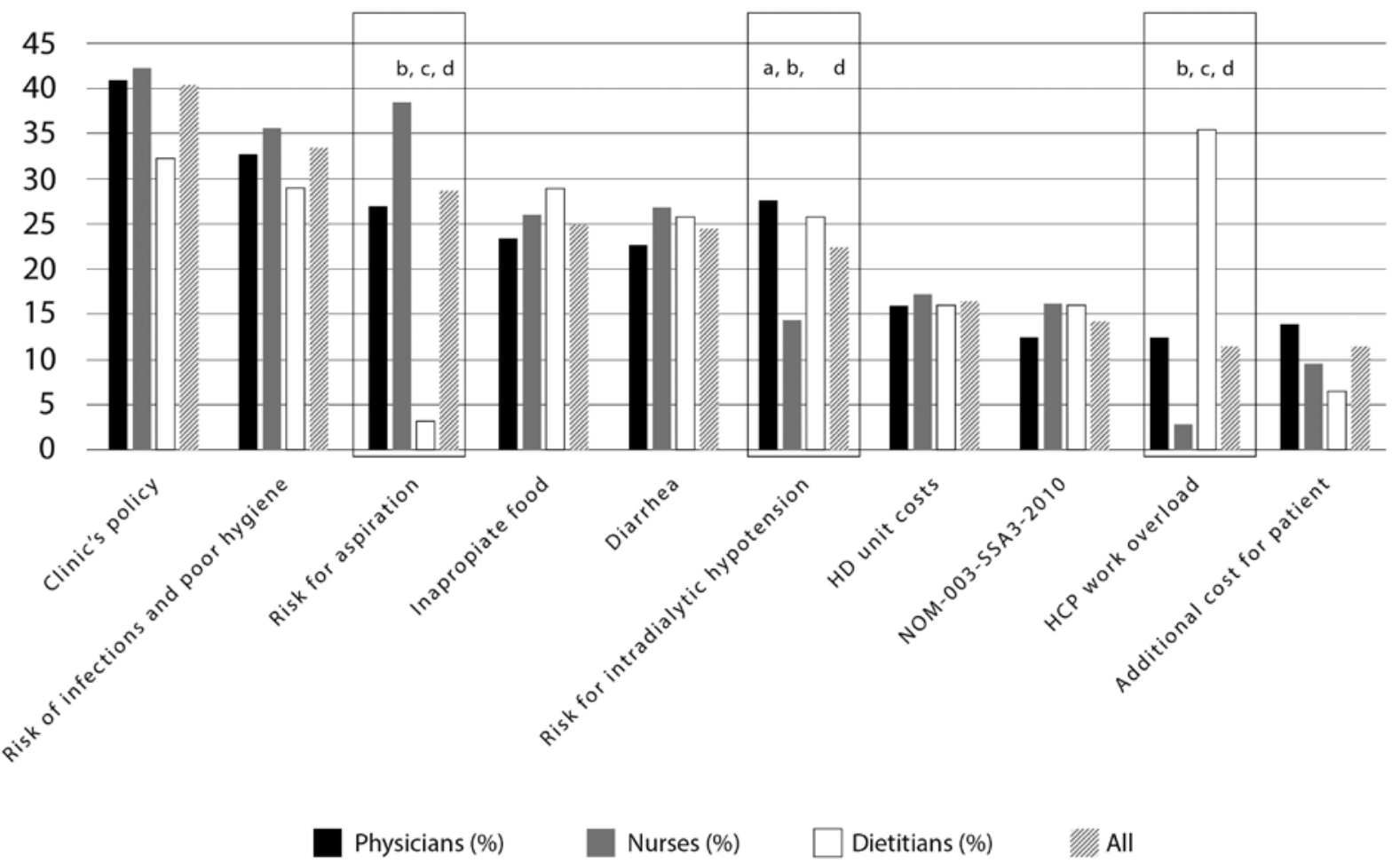

needs $^{6,7}$, ION might be a useful strategy to implement 26,27 .

In our survey, HCP were asked about the benefits of the use of ION. The most frequently mentioned were improvements in muscle anabolism (31.6\%), serum albumin (37.9\%), and QoL (54\%). These results are not different from those reported by Kistler et al. ${ }^{25}$, who also found that clinicians' opinions regarding the use of ION, among others, was an improvement in QoL. However, our respondents perceived not only benefits but also risks, being the most frequently mentioned intradialytic hypotension by our physicians, and bronchial aspiration by our nurses. It has been proposed that variables such as the energy content, volume or characteristics of consumed foods may be related to the incidence and prevalence of intradialytic hypotension ${ }^{16}$, although variations in the definition of this complication affect its reported prevalence. As an example, the reported prevalence of intradialytic hypotension under the simplest definition (a decrease of $\geq 20 \mathrm{mmHg}$ ) is $50-70 \%$; when the definition includes a clinical event and nursing interventions, the prevalence decreases by up to $7 \%^{19}$. Strong et al. ${ }^{18}$ analyzed 23 patients who brought their food to be consumed during the HD session, and the prevalence of intradialytic hypotension was $19 \%$. The study found that patients who consumed $>200 \mathrm{Kcal}$ during the session had a trend towards double the risk ( $p=0.058$ ) of presenting hypotension, 3 times more when consuming more than $200 \mathrm{ml}$ of liquids ( $p=0.011$ ), and required 5 times more mannitol ( $p=0.005$ ) with the consumption of liquids. The patients who preferred the intake of solid foods in the form of snacks were less likely to present hypotension ${ }^{18}$.

Kistler et al. ${ }^{25}$ mentioned that the most important concern, for both experienced and inexperienced HCP about oral supplementation during HD sessions, is intradialytic hypotension, although it rarely occurs in people who consume food during the session ${ }^{26-29}$. 
The concern that patients may develop intradialytic hypotension related to the consumption of food or supplements during an HD session is based on a theoretical-physiological notion involving hemodynamic redistribution, given that blood perfusion is concentrated in the digestive system, and a considerable volume of it circulates through the HD system. However, the studies that have evaluated these associations differ in the methods used and therefore, in their findings ${ }^{18-21}$.

Furthermore, many of the negative effects related to the consumption of food during HD may be reduced by a careful selection of candidates to ION based on their clinical condition. ${ }^{16}$ In fact, Benner et al. found fewer missed treatment days, fewer hospitalizations and no association with reduced dialysis efficacy in those patients treated with ION $^{29}$.

Kistler et al. ${ }^{25}$ found that about $70 \%$ of the European HCP participating in their survey provided food to patients during HD sessions (mostly dietitians), and almost all provided the food at no cost to patients. In contrast, in our country, only about $20 \%$ of the HCP surveyed had patients' consuming food during an HD session. Kistler et al. ${ }^{25}$ mentioned some reasons that may encourage clinicians to provide food during HD sessions. The two most frequently mentioned are: (1) it is an opportunity to provide additional energy ( $89 \%$ ) and (2) it can also be an opportunity to teach the patient about a proper diet (47\%). Finally, one of the main reasons why ION is not implemented in our HD centers is their clinic's policy based on the assumption that national regulations restrict it; however, there is no mention of this restriction in the Official Mexican Guidelines NOM-003-SSA3-2010 for the practice of HD nor in the document for the certification of $\mathrm{HD}$ units $^{30}$. On the other hand, policies of outsourced HD clinics may be another reason why this practice is not common. It is interesting to note that in our study, although intradialytic hypotension was the most important concern for HCP, it was not the main reason why food is not allowed during HD sessions. In the study of Kistler et al. ${ }^{25}$, intradialytic hypotension was infrequent according to $24 \%$ of the respondents, or even completely absent according to $34 \%$. Regarding the possibility that the presence of food leads to poor hygiene and the emergence of pests in the HD unit, $67 \%$ of the respondents said there was no risk of this happening, and $15 \%$ said it was very uncommon. With respect to the main reasons why ION was not a common practice in our HCP study, nurses perceived the risk for aspiration as a major problem while dietitians perceived this as a minor problem or maybe unlikely to happen. Intradialytic hypotension was perceived by physicians as a major reason why ION is not practiced, whereas nurses did not perceive so. Surprisingly, nurses perceived work overload as a minor reason why ION is not practiced, but dietitians perceived this as a major reason.

It is worth mentioning that even though some studies have shown a decrease in patient mortality with the use of $1 O N^{14,15}$, this outcome was not mentioned by the personnel surveyed in the present work, which suggests that the health personnel do not perceive this nutritional intervention as a clinical strategy to improve patient's survival.

Regarding the type of ION used, it should be noted that studies evaluating the use of both food and oral supplements have not shown one to be better than the other. Nutritional markers other than albumin and nitrogen balance have not been studied, including hand grip strength or physical functionality $^{31}$ or bioelectrical impedance. The present study found that HCP mostly perceives ION as a good opportunity to improve the QoL of HD patients, so it is important to evaluate this outcome. It also seems that the safety of ION is not certain, especially with respect to the risk of intradialytic hypotension or infections in HD patients. Nevertheless, the benefits seem to outweigh the risks, at least in theory.

The principal limitation of our study is related to those of survey studies in general, followed by the sample size, even considering previous calculation and the selection bias derived from the fact that the surveys were given to participants attending national medical meetings. On the other hand, the leading strengths and areas of opportunity for research are the evaluation of the cost-effectiveness 
of the use of ION, and the understanding of the possible reasons why this practice is not used in some countries despite the extensive evidence on its benefits reported in the literature.

The health-care personnel working in HD units perceived that ION has benefits related mainly to the QoL, but also that there are risks such as intradialytic hypotension, which have not been well described in literature. Therefore, we conclude that despite the well-defined benefits on nutritional markers such as an increase in serum albumin and the survival rate of the patients, the implementation of this practice in our country is not an easy task. ION is used in only $22 \%$ of the HD units found in our country, mainly because it is prohibited by the clinic's policy for these units.

\section{ACKNOWLEDGMENTS}

The authors acknowledge the positive response to the survey from all participants.

\section{REFERENCES}

1. Carrero JJ, Thomas F, Nagy K, Arogundade F, Avesani CM, Chan $M$, et al. Global prevalence of protein-energy wasting in kidney disease: a meta-analysis of contemporary observational studies from the international society of renal nutrition and metabolism. J Ren Nutr. 2018;28:380-92

2. Antón-Pérez G, Santana-Del-Pino Ä, Henríquez-Palop F, Monzón T, Sánchez AY, Valga F, et al. Diagnostic usefulness of the protein energy wasting score in prevalent hemodialysis patients. J Ren Nutr. 2018;28:428-34.

3. Fouque D, Kalantar-Zadeh K, Kopple J, Cano N, Chauveau P, Cuppari L, et al. A proposed nomenclature and diagnostic criteria for protein-energy wasting in acute and chronic kidney disease. Kidney Int. 2008;73:391-8.

4. Sabatino A, Piotti G, Cosola C, et al. Dietary protein and nutritional supplements in conventional hemodialysis. Semin Dial. 2018;31:583-91.

5. Carrero JJ, Stenvinkel P, Cuppari L, Gandolfini I, Kooman JP, Fiaccadori $E$, et al. Etiology of the protein-energy wasting syndrome in chronic kidney disease: a consensus statement from the international society of renal nutrition and metabolism (ISRNM). J Ren Nutr. 2013:23:77-90.

6. Burrowes JD, Larive B, Cockram DB, Dwyer J, Kusek JW, McLeroy $S$, et al. Effects of dietary intake, appetite, and eating habits on dialysis and non-dialysis treatment days in hemodialysis patients: cross-sectional results from the HEMO study. J Ren Nutr. 2003;13:191-8.

7. González-Ortíz AJ, Domínguez-Zambrano EL, Correa-Rotter R, Espinosa-Cuevas MA. Patterns of Food Consumption and Eating Habits of Mexican Population on Dialysis and Non-Dialysis Treatment Days in Hemodialysis Patients. Genova, Italy: Poster Presented at XIX Congress of the International Society of Renal Nutrition and Metabolism; 2018.
8. Brown RO, Compher C, American Society for Parenteral and Enteral Nutrition Board of Directors. A.S.P.E.N. clinical guidelines: nutrition support in adult acute and chronic renal failure. JPEN J Parenter Enteral Nutr. 2010;34:366-77.

9. Kalantar-Zadeh K, Cano NJ, Budde K, Chazot C, Kovesdy CP, Mak RH, et al. Diets and enteral supplements for improving outcomes in chronic kidney disease. Nat Rev Nephrol. 2011; 7:369-84

10. Zabel R, Ash S, Bauer J, King N. Assessment of subjective appetite sensations in hemodialysis patients. Agreement and feasibility between traditional paper and pen and a novel electronic appetite rating system. Appetite. 2009; 52:525-7.

11. Kistler BM, Fitschen PJ, Ikizler TA, Wilund KR. Rethinking the restriction on nutrition during hemodialysis treatment. J Ren Nutr. 2015;25:81-7.

12. Ikizler TA, Cano NJ, Franch H, Fouque D, Himmelfarb J, KalantarZadeh $\mathrm{K}$, et al. Prevention and treatment of protein energy wasting in chronic kidney disease patients: a consensus statement by the international society of renal nutrition and metabolism. Kidney Int. 2013:84:1096-107.

13. Pupim LB, Majchrzak KM, Flakoll PJ, Ikizler TA. Intradialytic oral nutrition improves protein homeostasis in chronic hemodialysis patients with deranged nutritional status. J Am Soc Nephrol. 2006:17:3149-57.

14. Lacson E Jr., Wang W, Zebrowski B, Wingard R, Hakim RM. Outcomes associated with intradialytic oral nutritional supplements in patients undergoing maintenance hemodialysis: a quality improvement report. Am J Kidney Dis. 2012; 60:591-600.

15. Weiner DE, Tighiouart H, Ladik V, Meyer KB, Zager PG, Johnson $D S$, et al. Oral intradialytic nutritional supplement use and mortality in hemodialysis patients. Am J Kidney Dis. 2014;6 3:276-85.

16. Kistler BM, Benner D, Burrowes JD, Campbell KL, Fouque D, Garibotto G, et al. Eating during hemodialysis treatment: a consensus statement from the international society of renal nutrition and metabolism. J Ren Nutr. 2018;28:4-12.

17. Kalantar-Zadeh $\mathrm{K}$, Ikizler TA. Let them eat during dialysis: an overlooked opportunity to improve outcomes in maintenance hemodialysis patients. J Ren Nutr 2013;23:157-63.

18. Strong J, Burgett M, Buss ML, Carver M, Kwankin S, Walker D. Effects of calorie and fluid intake on adverse events during hemodialysis. J Ren Nutr. 2001;11:97-100

19. Benaroia M, lliescu EA. Oral intake during hemodialysis: is there an association with intradialytic hypotension? Hemodial Int. 2008; $12: 62-5$

20. Sivalingam M, Banerjee A, Nevett G, Farrington K. Haemodynamic effects of food intake during haemodialysis. Blood Purif. 2008;26:157-62

21. Borzou SR, Mahdipour F, Oshvandi K, Salavati M, Alimohammadi N. Effect of mealtime during hemodialysis on patients' complications. J Caring Sci. 2016;5:277-86.

22. Hernández-Ávila M, Rivera-Dommarco J, Shamah-Levy TL, et al. Encuesta Nacional de Salud y Nutrición de Medio Camino 2016 (ENSANUT). Instituto Nacional de Salud Pública, México: ENSANUT; 2016. p. 1-154.

23. Faul $F$, Erdfelder E, Lang AG, Buchner A. G*Power 3: a flexible statistical power analysis program for the social, behavioral, and biomedical sciences. Behav Res Methods. 2007:39: 175-91.

24. Fouque D, McKenzie J, de Mutsert R, Azar R, Teta D, Plauth M, et al. Use of a renal-specific oral supplement by haemodialysis patients with low protein intake does not increase the need for phosphate binders and may prevent a decline in nutritional status and quality of life. Nephrol Dial Transplant. 2008; 23:2902-10.

25. Kistler B, Benner D, Burgess M, Stasios M, Kalantar-Zadeh K, Wilund KR, et al. To eat or not to eat-international experiences with eating during hemodialysis treatment. J Ren Nutr. 2014; 24:349-52

26. Sezer S, Bal Z, Tutal E, Uyar ME, Acar NO. Long-term oral nutrition supplementation improves outcomes in malnourished patients with chronic kidney disease on hemodialysis. JPEN J Parenter Enteral Nutr. 2014;38:960-5.

27. Caetano C, Valente A, Silva FJ, Antunes J, Garagarza C. Effect of an intradialytic protein-rich meal intake in nutritional and body composition parameters on hemodialysis patients. Clin Nutr ESPEN. 2017;20:29-33.

28. Choi MS, Kistler B, Wiese GN, Stremke ER, Wright AJ, Moorth $\mathrm{RN}$, et al. Pilot study of the effects of high-protein meals dur- 
ing hemodialysis on intradialytic hypotension in patients undergoing maintenance hemodialysis. J Ren Nutr. 2019;29: $102-11$

29. Benner D, Brunelli SM, Brosch B, Wheeler J, Nissenson AR. Effects of oral nutritional supplements on mortality, missed dialysis treatments, and nutritional markers in hemodialysis patients. J Ren Nutr. 2018:28:191-6.
30. Norma Oficial Mexicana NOM-003-SSA3-2010, Para la práctica de la hemodiálisis. Diario Oficial de la Federación, 8 de Julio de 2010. 31. Martin-Alemañy G, Valdez-Ortiz R, Olvera-Soto G, Gomez-Guerrero I, Aguire-Esquivel G, Cantu-Quintanilla G, et al. The effects of resistance exercise and oral nutritional supplementation during hemodialysis on indicators of nutritional status and quality of life. Nephrol Dial Transplant. 2016:31:1712-20. 